\title{
CATARACT EXTRACTION UNDER GENERAL ANAESTHESIA* \\ A CONSIDERATION OF 100 CASES
}

\author{
BY \\ J. GIBSON MOORE \\ Edgware, Chase Farm, and Bolingbroke Hospitals, London
}

IT seemed worthwhile confirming the work of Cridland (1955) who recorded a series of cataract extractions under general anaesthesia at a time when this method was used only by a minority.

General anaesthesia for all ophthalmic surgery has come to stay. It would not be right to be dogmatic as more work needs to be done but, provided the patient is in satisfactory health, it merits serious consideration for all major intra-ocular operations. There is little need to reiterate the advantages, but the most important one is that the average surgeon will be a better performer and obtain better and more uniform results if he has no longer to contend with the reactions of the patient during operation.

Skilled anaesthesia is, of course, essential, and we are fortunate that this is readily available in Great Britain. The majority of the cases in this series were handled by anaesthetists of registrar status using standard technique. It will be noted that an endotracheal tube was passed in all cases, and this is in agreement with the opinion of Sandiford $(1955,1957)$ as it gives the anaesthetist a much higher degree of control than the pharyngeal tube used by Harper (1956). Neither ether nor chloroform was used in any concentration, but at one hospital fluothane was used in a few cases with satisfactory results.

There were, of course, small differences of procedure between the anaesthetists who gave their advice so freely, but an average routine is given in detail.

\section{Procedure}

The patient is admitted 2 days before operation. Chloral hydrate $15 \mathrm{gr}$. is given on the first night, and on the second night Phenergan $25 \mathrm{mg}$. is given by mouth to sedate and prevent or relieve bronchospasm and possibly to reduce post-operative vomiting.

Premedication is by atropine $1 / 100 \mathrm{gr}$. and pethidine $50 \mathrm{mg}$. by injection one hour pre-operatively.

Induction is by a sleeping dose of 2.5 per cent. thiopentone followed by suxamethonium $50 \mathrm{mg}$. given through a Mitchell needle.

The vocal cords are sprayed with 5 per cent. Xylocaine and an endotracheal tube greased with 2 per cent. Xylocaine ointment is inserted. The anaesthetic is maintained on nitrous oxide and oxygen 6 litres to 2 litres, and intermittent small doses of pethidine are injected as required. 
At the conclusion of the operation, pharyngeal toilet is performed as necessary, the endotracheal tube is removed, and a pharyngeal tube is inserted when the patient's reflexes will tolerate this.

The patient is usually awake on return to the ward and is encouraged to sit up and do deep breathing exercises. Coughing and vomiting are minimal.

Chloral hydrate 15 gr. is given the same night.

Corneo-scleral sutures are now probably used by most surgeons. They are even more essential under general anaesthesia and a word on their use may not be out of place.

There must be an increased risk, however slight, of coughing and vomiting after general anaesthesia, but there need not be the slightest anxiety if the wound is adequately sutured. It is useful to have one pre-placed groove suture as this can be drawn tight at any stage and it can be used to raise the cornea for intraocular procedures. Two additional post-placed sutures are used as a routine, and if the wound shows any sign of inaccurate apposition as many as four more can be inserted with advantage.

The introduction of air into the anterior chamber is now a routine procedure and if the air shows any sign of escaping it is a firm indication that more sutures are required.

The removal of sutures is often an anxious procedure; early removal is not necessary unless the sutures are causing gross irritation and then I would not hesitate in requesting a second general anaesthetic. The majority can be left to cut out spontaneously; this usually occurs after about 4 weeks when the remainder can be removed easily as the wound is well healed.

\section{Results}

These are no more spectacular than any other average series of cases (Table).

TABLE

RESULTS IN 100 CASES

\begin{tabular}{|c|c|c|c|c|c|}
\hline \multicolumn{5}{|c|}{ Particulars } & \multirow{2}{*}{$\begin{array}{c}\text { No. of Cases } \\
59 \\
16 \\
12\end{array}$} \\
\hline Visual Acuity & $\begin{array}{l}6 / 6 \\
6 / 9 \text { to } 6 / 12 \\
\text { Less than } 6 / 60\end{array}$ & $\begin{array}{l}\ldots \\
\cdots \\
\cdots\end{array}$ & $\begin{array}{l}\cdots \\
\cdots \\
\cdots\end{array}$ & $\begin{array}{l}\ldots \\
\cdots\end{array}$ & \\
\hline Complications & $\begin{array}{l}\text { Iris prolapse ... } \\
\text { Vitreous loss ... } \\
\text { Scoop extraction } \\
\text { Retinal detachment } \\
\text { Eye lost } \quad . .\end{array}$ & $\begin{array}{l}\ldots \\
\cdots \\
\cdots \\
\cdots\end{array}$ & $\begin{array}{l}\cdots \\
\cdots \\
\cdots \\
\cdots\end{array}$ & $\begin{array}{l}\ldots \\
\cdots \\
\cdots \\
\cdots\end{array}$ & $\begin{array}{r}5 \\
2 \\
\mathrm{Nil} \\
1 \\
2 *\end{array}$ \\
\hline \multirow[t]{2}{*}{ Route of Extraction } & $\begin{array}{l}\text { Intracapsular ... } \\
\text { Extracapsular.. }\end{array}$ & $\begin{array}{l}\cdots \\
\cdots\end{array}$ & $\begin{array}{l}\ldots \\
\cdots\end{array}$ & $\begin{array}{l}\ldots \\
\ldots\end{array}$ & $\begin{array}{l}46 \\
54\end{array}$ \\
\hline & Total .. & . & . & .. & 100 \\
\hline
\end{tabular}

* One infection, one gross iris prolapse (self-inflicted).

Complications.-These have occurred and an occasional eye has been lost, but even so general anaesthesia is so comfortable for the patient and the surgeon that it is now the method of choice in these three hospitals. 
Iris Prolapse.-This is always a liability. In none of the five cases in which it occurred however, did it appear before the second post-operative day, and therefore it cannot be attributed to the anaesthetic.

Hyphaema was not encountered. This complication has largely disappeared because of the use of corneo-scleral suturing.

Visual Acuity.-A visual acuity of $6 / 6$ was achieved in only about 60 per cent. of cases. This was not due to high astigmatism which averaged only $1 \cdot 5 \mathrm{D}$, but many patients with apparently perfect results refused to see better than $6 / 9$ although the reading vision was satisfactory and the macula apparently normal. This point was noted by Glover (1954).

There were two complications of a general nature which might be attributed to the anaesthetic. One patient was a misdiagnosed case of myotonia dystrophica and extreme anxiety was caused by failure to maintain spontaneous respiration after operation. This case has been reported elsewhere (Bourke and Zuck, 1957), and emphasizes that a full pre-operative examination must be undertaken if general anaesthesia is to be used. The second patient sustained a minor coronary thrombosis on the fifth post-operative day, but this might have been due to the acceleration of a pending occurrence.

\section{Summary}

General anaesthesia is the method of choice for cataract surgery in these three hospitals. It is safe and comfortable for both surgeon and patient. One hundred cases are briefly considered and the technique used given in detail.

My thanks are due to Drs. D. Zuck, P. W. Spencer Gray, and J. S. E. Manley, consultant anaesthetists, and to their registrars, from whose anaesthetic procedures and advice I have quoted freely.

\section{REFERENCES}

Bourke, T. D., and ZuCK, D. (1957). Brit. J. Anaesth., 29, 35.

CRIDland, N. (1955). Trans. ophthal. Soc. U.K., 75, 563.

GLOVER, E. C. (1954). Ibid., 74, 145.

HARPER, J. K. (1956). Brit. J. Ophthal., 40, 661.

SANDIFORD, H. B. C. (1955). Trans. ophthal. Soc. U.K., 75, 575. (1957). Brit. J. Anaesth., 29, 319.

\section{ADDENDUM}

Since the submission of the above article a further 72 cataracts have been operated upon under general anaesthesia. The results have been uniformly satisfactory. No eye was lost. There was only one iris prolapse and no case of vitreous loss. Hyphaema of more than one millimetre occurred in only one case. When these figures are added to those given above, it may reasonably be concluded that general anaesthesia is satisfactory as far as the eye itself is concerned. The general picture, however, is not quite so certain. One woman aged 73 sustained a coronary thrombosis on the 11 th day after operation and died. It is difficult to know to what extent this should be attributed to the anaesthetic as it came without warning, but clearly great care must be taken with frail old people. 